\title{
Electrical Impedance Tomographic Methods for Sensing Strain Fields and Crack Damage in Cementitious Structures
}

\author{
TSUNG-ChIN Hou AND JeROME P. LYNCH* \\ Department of Civil \& Environmental Engineering, University of Michigan, Ann Arbor, MI 48109-2125, USA
}

\begin{abstract}
Cement-based composites (for example, concrete) are brittle materials that crack when loaded in tension. Current strategies for crack detection are primarily based upon visual inspection by an inspector; such approaches are labor-intensive and expensive. Direly needed are sensors that can be included within a structural health monitoring (SHM) system for automated quantification of crack damage. This study explores the use of cementitious materials as their own sensor platform capable of measuring mechanical behavior under loading. Fundamentally, this self-sensing functionality will be based upon electro-mechanical properties. First, the piezoresistivity of cementitious composites is quantified so as to establish the material as a multifunctional system capable of self-sensing. Second, electrical impedance tomography (EIT) is proposed for measuring internal strain fields using only electrical measurements taken along the boundary of the structural element. An inherent advantage of EIT is that it is a distributed sensing approach offering measurement of strain fields across 2D or $3 \mathrm{D}$. Furthermore, the approach is well suited for imaging cracks which appear as conductivity reductions in EIT-derived conductivity maps. Finally, to validate the accuracy of the EIT technique, it is applied to fiber reinforced cementitious composite elements loaded by axial tension-compression cycles and 3-point bending.
\end{abstract}

Key Words: electrical impedance tomography, multifunctional materials, structural health monitoring, crack detection, fiber reinforced cementitious composites.

\section{INTRODUCTION}

C RACKING in cement-based structures, such as those constructed of reinforced concrete, can result from a variety of factors including externally applied loads, shrinkage, poor construction methods, among many others. When making an assessment of the general state of health of such structures, cracks must be reliably quantified and their significance determined. For example, small cracks affecting only the external aesthetic of the structure should be differentiated from those that reduce its strength, stiffness, and long-term durability (ACI, 1998). Detailed visual inspection of the surface of the structure remains a common method for detecting cracks; systematic crack mapping allows inspectors to monitor the progression of cracks and to hypothesize the nature of their origins (Bungey et al., 2006). After suspicious cracks are encountered, nondestructive (for example, ultrasonic inspection) and partially destructive (for example, core holes) testing can be carried out by trained inspectors to determine crack features below the structural surface (ACI, 1998). However, all of these methods require the use of trained

*Author to whom correspondence should be addressed. E-mail: jerlynch@umich.edu

Figures 1-15 appear in color online: http://jim.sagepub.com personnel to execute, rendering them as tedious and expensive. In contrast, automated sensor technologies are needed for permanent installation so that accurate assessments of crack damage could be made without requiring a trained professional to visually inspect the structure.

A variety of approaches have been proposed for automated structural health monitoring of concrete structures. Generally, many of these approaches call for the installation of external sensors to measure global and local structural responses to loading. Early work explored the use of vibration measurements (for example, accelerations) to identify global modal properties that change when structural damage is present. Particularly for civil structures, environmental variability often hinders accurate correlation of modal property changes to damage (Doebling et al., 1998). Alternatively, local structural measurements including strain and deformation have also been proposed for crack detection. Based on the applied structural loading and the corresponding component response, various damage index methods have been proposed for the quantification (often on a scale from 0 to 1 ) of cracking degree (Park and Ang, 1985; Kratzig et al., 1989). While damage index models perform well when predicting cracks in laboratory elements, the inability to precisely 
measure loads on full-scale concrete structures renders this approach difficult to apply in more practical settings.

Perhaps the best approach for automated structural health monitoring of concrete structures entails the adoption of the sensors available in the nondestructive evaluation (NDE) field. In particular, passive and active stress wave approaches have been proposed for NDE evaluation of concrete structures. Acoustic emission (AE) sensing is foremost amongst the passive stress wave methods. AE employs piezoelectric elements to capture the stress waves generated by cracks (Ouyang et al., 1991; Shah and Choi, 1999); while AE has played a critical role in the laboratory, its success in the field has been limited to only a handful of applications (Mindess, 2004). In contrast, active stress wave methods have proven more accurate for crack detection. Active sensing entails the use of piezoelectric transducers to introduce short ultrasonic stress waves into a concrete element and using the same transducer, or another, to measure the stress waves after they have propagated through the element. For example, pulse-echo (using one transducer) and pitch-catch (using two transducers) techniques are capable of characterizing cracks in actual concrete structures (Carino, 2004). In structural elements whose geometry guides the stress wave in a specific direction, the ultrasonic stress waves are termed guided waves (Raghavan and Cesnik, 2007); some examples of guided wave techniques to characterize damage in concrete include $\mathrm{Na}$ et al. (2002), Luangvilai et al. (2002), and Jung et al. (2000). A direct extension of the active stress wave approach is the electromechanical impedance spectra method where the electromechanical impedance spectrum of a piezoelectric transducer is used to detect cracking in the vicinity of the transducer (Park et al., 2000; Park et al., 2006). Some challenges associated with active sensing in cement-based materials include significant wave attenuation over long distances and internal heterogeneities causing wave scattering and complex ultrasonic speckle patterns.

Compared to other NDE methods, utilization of the electrical properties of cement-based materials for crack detection has garnered less attention from the civil engineering community. Historically, electrical properties have been investigated for tracking the formation of microstructural properties during hardening (Han et al., 2005) and to quantify the potential for corrosion of buried steel reinforcement (Lauer, 2004). In contrast, this study will utilize the electrical properties of cementitious materials as a novel approach to automated health monitoring of civil structures. First, the relationship between electrical conductivity and strain will be quantified so that it can be established that cement-based materials are self-sensing. Since in theory a measurement for strain can be made wherever the material is, a novel approach to measuring conductivity over spatial areas is introduced next. Termed electrical impedance tomography (EIT), this inverse tomographic approach offers 2D and 3D conductivity maps for structural elements instrumented with electrodes upon their surface. Conceptually, the EIT approach is similar to the ultrasonic tomographic methods (Rose and Ditri, 1990) used to map wave attenuation properties of structural elements using dense arrays of surface-mounted piezoelectric transducers. As a result of cement being piezoresistive, EIT conductivity maps offer a direct measurement of strain fields. Furthermore, cracks can be imaged as conductivity reductions since cracks are non-conducting across their widths. While applicable to any cement-based composite, the paper presents the experimental investigation of the application of EIT to image strain fields and cracks in fiberreinforced cementitious composite (FRCC) structural elements.

\section{ELECTRICAL CONDUCTION IN CEMENTITIOUS MATERIALS}

Conductivity $(\sigma)$ is a fundamental material property that quantifies the ability of the material to carry a current when placed in an electrical field. Specifically, the current flow density, $J$, is linearly proportional to the electric field, $E$, through conductivity (Mayer and Lau, 1990): $J=\sigma E$. Resistivity $(\rho)$, the inverse of conductivity, is the volumetric resistance, $R$, of a unit cube as measured across one dimension. Resistivity is reported in terms of $\Omega$-m while conductivity is reported using the units $\mathrm{S} \mathrm{m}^{-1}\left(\Omega^{-1} \mathrm{~m}^{-1}\right)$. With conductivities ranging from $10^{-3}$ to $10^{-6} \mathrm{~S} \mathrm{~cm}^{-1}$, cementitious materials are classified as semiconductors (Whiting and Nagi, 2003). In cement, the current generated by an electric field is based on ionic conduction. The high concentration of calcium, potassium, and sodium salts within the pore water and water-cement gel are mobilized by the electric field to create electrical current (Hansson and Hansson, 1983). Since the ions in water are the primary charge carrier, the conductivity of cementitious materials naturally exhibit strong dependency on moisture content.

Considerable attention has been paid in recent years to measuring and interpreting the electrical properties of cement composites including reinforced concrete. Specifically, the electrical properties of cement can be used to assess the microstructural details of the material (Han et al., 2005). For example, very early work in the field explored correlations between direct current (DC) conductivity measurements and the setting times of Portland cement composites (Calleja, 1953; Hammond and Robson, 1955). More profound insight to the hydration process has been gained since the 1990's through the use of electrical impedance spectroscopy (EIS). EIS measures conductivity as a function of the 
angular frequency of an applied alternating current (AC) signal (McCarter and Brousseau, 1990). Impedance spectra obtained by EIS can be used to track hydration processes, identify the porosity of cured cement, and characterize interfacial properties (for example, cement-steel or cement-aggregate interfaces). The electrical properties of cement also serve as a basis for assessing the corrosion potential of reinforced concrete (Lauer, 2004). When reinforcement steel corrodes, the cement conductivity is a measure of how easy it is for ions to flow between the anodic and cathodic sites on the buried reinforcement. It has not been until very recently that the electrical properties of cementitious materials have been explored for damage detection including the identification of cracking (Peled et al., 2001; Chung, 2001; Hou and Lynch, 2005a).

\section{Traditional Electrical Measurement Techniques}

Multiple measurement methods have been proposed for measuring the conductivity of cement-based materials. In general, the measurement methods proposed can be broadly classified as either 2-point or 4-point probe methods. In the 2-point probe methods (Figure 1(a)), two electrodes are used to apply an electrical current, $I$, and to also measure the corresponding drop in voltage, $V$, across the cement specimen. Electrodes must be in intimate contact with the cement-based specimen to induce an ionic current within the specimen. Metallic electrodes can either be surface mounted using conductive gels and pastes, or they can be embedded directly into the wet concrete prior to hardening (Whiting and Nagi, 2003). If a DC is applied across the specimen area, conductivity can be calculated,

$$
\sigma=\frac{I}{V} \frac{L}{w h}
$$

where $L, w$, and $h$ correspond to the electrode spacing, specimen width, and specimen height, respectively. While 2-point DC probe measurements are easy to take, they do suffer from two major drawbacks. First, contact impedance at the electrode-cement interface in
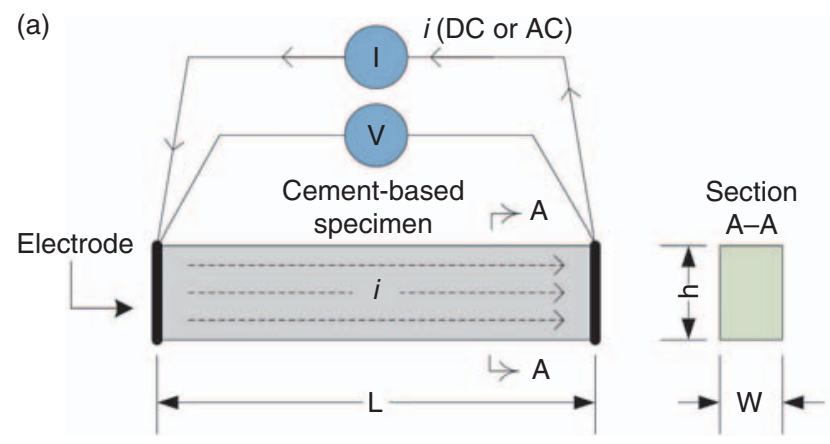

the 2-point probe method introduces a time-dependent reduction in conductivity. Contact impedance originates from the electrochemical reactions that naturally occur in the test specimen in the vicinity of the electrode (Vilhunen et al., 2002). For example, electrons flowing into a specimen at the electrode induce pore water to decompose into hydrogen $\left(\mathrm{H}_{2}\right)$ and hydroxide ions $\left(\mathrm{OH}^{-}\right)$(Hansson and Hansson, 1983). Similarly, free hydroxide ions can react at the other electrode to produce electrons $\left(\mathrm{e}^{-}\right)$that then flow into the electrode as well as producing oxygen $\left(\mathrm{O}_{2}\right)$ and water $\left(\mathrm{H}_{2} \mathrm{O}\right)$. These reaction byproducts accumulate at the electrodespecimen interface resulting in a back electromagnetic field. The second drawback of DC 2-point methods is the measurement error introduced by polarization of the specimen. Polarization is the separation of positive and negative ions trapped within the cement pores; as ions separate, less current is carried resulting in a reduction in the conductivity measurement (Hansson and Hansson, 1983). As a result, AC is preferred since contact impedance and polarization effects do not have sufficient time to develop under an alternating field (Whiting and Nagi, 2003). When AC signals are used in the 2-point probe method, Equation (1) is still valid using the amplitude of the current and voltage.

The 4-point probe method is the preferred approach for measuring the conductivity of cement-based materials (Millard, 1991). As the name suggests, the method employs four independent electrodes along the length of a specimen (Figure 1(b)). The two outer-most electrodes are used to drive an electric current (DC or AC) into the medium while the two inner electrodes are responsible for measuring the electrical potential developed over the length, $L$. Again, if it is assumed the cross-sectional area of the specimen is $w$ by $h$, then Equation 1 is still valid. In the 4-point probe method, the effects of contact impedance are minimized because the measurement and excitation electrodes are separated. As a result, 4-point probe methods provide a more consistent measurement of electrical conductivity when compared to 2-point probe methods.

A specialized version of the 4-point probe method is the Wenner technique (Gowers and Millard, 1999).

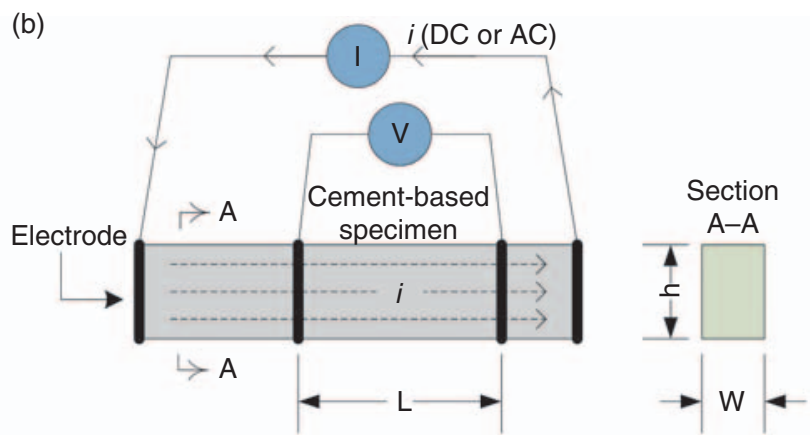

Figure 1. Conductivity measurement based upon the (a) 2-point and (b) 4-point probe techniques. 
Although, this approach was originally developed for in-situ measurement of soil conductivity, it has been widely applied to measurements in cementitious materials. In the Wenner technique, four electrodes equally spaced (by a) along a straight line are applied to the surface of a cementitious specimen, as shown in Figure 2. If the specimen is assumed to be an infinite half-space, then conductivity can be calculated:

$$
\sigma=\frac{I}{V} \frac{1}{2 \pi a}
$$

Both DC and AC electrical excitations can be used, but generally AC excitations greater than $100 \mathrm{~Hz}$ are preferred (Han et al., 2005). Some care must be exercised when using the Wenner technique. For example, test specimens must be sufficiently thick (generally, thicknesses 4 times greater than the electrode spacing) to ensure the assumption of an infinite half space is valid. Similarly, measurements must be made away from specimen edges and corners.

EIS is a more sophisticated electrical characterization technique based on AC signals. Similar to the aforementioned 4-point probe measurement method, two probes are employed to apply an AC signal to the specimen while two inner electrodes measure voltage (Figure 3(a)). In EIS, a frequency response analyzer (FRA) is adopted to measure both the amplitude and phase of the voltage measurement relative to the applied sinusoidal current (Barsoukov and Macdonald, 2005). Using amplitude and phase, $\theta$, the complex-valued impedance of the material can be measured as a function

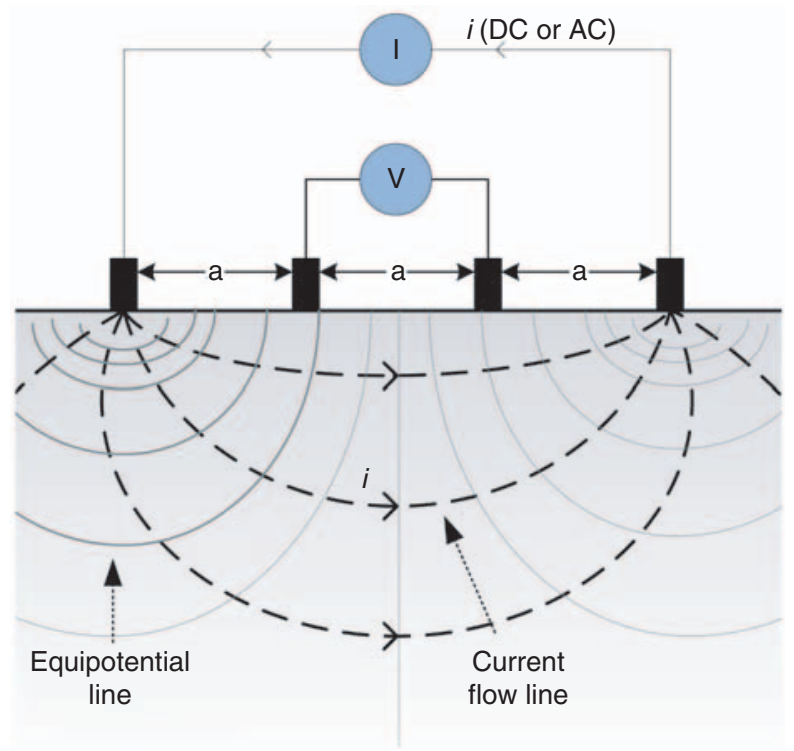

Figure 2. Wenner technique: a 4-point probe conductivity measurement based upon surface contact (adapted from Millard (1991)). of applied AC frequency, $\omega$. The frequency is varied from low to high frequencies with complex impedance,

$$
Z=\frac{V_{A} \sin (\omega t+\theta)}{I_{A} \sin (\omega t)}
$$

plotted on the complex plane. The real and imaginary components are associated with the conductivity and capacitive properties of the specimen, respectively. For many cementitious materials, the impedance plot consists of two semi-circular traces as shown in Figure 3(b). The low-frequency semi-circular trace corresponds to the behavior of the electrode while the high frequency trace corresponds to that of the cementitious material (Han et al., 2005). Such distinctive impedance plots also permit the use of equivalent parallel resistor-capacitor (RC) circuits (Figure 3(c)) to model the electrical behavior of the material.

\section{Self-sensing Fiber Reinforced Cementitious Composites}

While concrete continues to be a dominant material used in the design of large civil structures, the material is

(a)
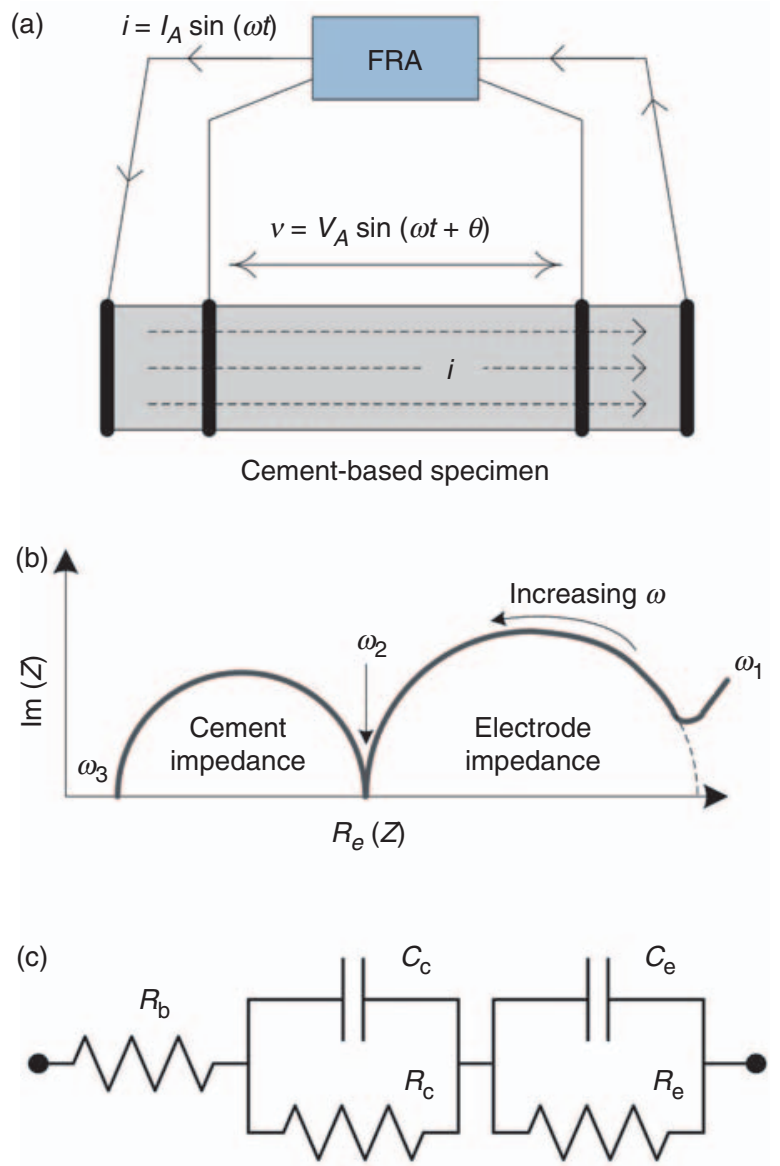

Figure 3. Electrical impedance spectroscopy: (a) experimental setup; (b) typical impedance plot on the complex plane (adapted from Han et al. (2005)); and (c) equivalent circuit model. 
inherently brittle and prone to cracking when loaded in tension. Short fibers have been proposed in lieu of coarse aggregates to enhance the mechanical properties of the cement matrix (Balaguru and Shah, 1992). A variety of fiber types have been proposed in the literature including polymeric, metallic, and carbon fibers. FRCC can be designed to exhibit strength and ductility in tension, thereby rendering them attractive for use in tension- and shear-dominated structural elements. Optimization of the fiber-matrix interface by mechanical (for example, hooked fibers) or chemical (for example, fiber coatings) leads to energy dissipation by thin microcracks whose formation is arrested by the fibers. This micro-scale behavior leads to tensile strain-hardening and high damage tolerance in tension (ParraMontesinos, 2005). In recent years, strain-hardening FRCC materials have found application in the design of coupling beams in shear walls (Wight et al., 2006), bridge decks (Kim et al., 2004; Naaman and Chandrangsu, 2004), retaining walls (Kunieda and Rokugo, 2006), and extruded pipes (Stang and Pedersen, 1996).

Because of the growing importance of FRCC materials, this study will explore their electrical properties for sensing the mechanical behavior of FRCC structural elements. Other researchers have also begun to study the piezoresistivity (i.e., strain induced resistivity changes) of FRCC materials with the aim of using them as their own sensors (Chung, 2001; Reza et al., 2003; Hou and Lynch, 2005b; Li et al., 2006). The addition of sensing functionality with mechanical functionality has led to FRCC being classified as a 'multifunctional' material (Chung, 2003).

Prior to cracking, change in FRCC resistivity occurs linearly with strain in both tension and compression. For example, the piezoresistive properties of FRCC plate elements employing polymeric and steel fibers have been studied by Hou and Lynch (2005b). As shown in Figure 4(a), the 2-point probe method assisted by a digital multimeter is used to measure the change in material conductivity as tensile strain is applied to each FRCC element. The stress-strain curves (Figure 4(b)) for the two plates reveal ductile strain-hardening behavior.
Resistivity-strain curves (Figure 4(c)) also reveal fairly linear trends for each fiber type.

\section{ELECTRICAL IMPEDANCE TOMOGRAPHY}

Two- and four-point probe methods suffer from inherent limitations when used to characterize the electrical properties of cementitious materials. For example, they do not provide a measurement of material conductivity at a given point; rather, they measure the average conductivity between the electrodes. Therefore, if the electrodes are spaced too far apart, inhomogeneities that may exist between the electrodes are not directly observed since their influence on the conductivity measurement is averaged out. Should a mapping of conductivity over the area of a cement element be sought, the Wenner technique can be employed. Numerous vendors sell hand-held equipment to make 4-point probe conductivity measurements based on the Wenner technique (Bungey et al., 2006). However, repeated measurement across a structural element can be both labor-intensive and time-consuming.

An autonomous means of measuring the spatial distribution of FRCC conductivity is sought. Since FRCC materials are piezoresistive, conductivity maps could be used to measure 2D strain fields within an FRCC structural element. Furthermore, cracks are physical inhomogeneities that block the flow of electricity; cracks would therefore appear as regions of near zero conductivity within the conductivity maps. EIT is proposed herein for mapping the spatial distribution of conductivity over structural surfaces. EIT has been widely adopted for anomaly detection in geophysical exploration (Zhdanov and Keller, 1994) and biomedical imaging (Webster, 1990).

EIT is a more sophisticated approach to measuring material conductivity than that of the two- and fourprobe methods. Unlike the probe methods, EIT is a combination of both electrical probing followed by the use of analytical models describing the flow of electricity in the test specimen. Therefore, conductivity mapping by
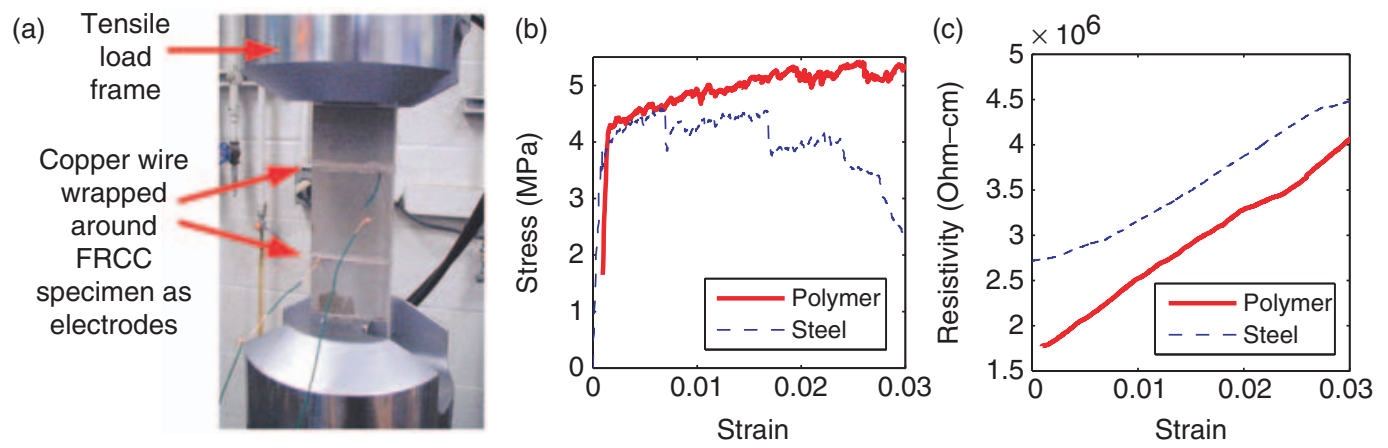

Figure 4. (a) FRCC plate element loaded in monotonic axial tension as resistivity is measured by 2-point probing. (b) stress and (c) resistivity vs strain plots for polymeric and steel fiber FRCC plates. 
EIT can be broken down into three major parts. First, the specimen under study is stimulated by a regulated current while electrical voltages are measured along the specimen boundary. Second, an analytical model that predicts the boundary voltages to the same AC stimulation is formulated; this model is often referred to as the forward problem since the distribution of conductivity is assumed known. However, the conductivity distribution is unknown; hence, the inverse problem is solved by varying the assumed conductivity distribution of the forward problem until convergence between experiment and model is achieved. Figure 5 summarizes the EIT approach to conductivity determination.

\section{Electrical Stimulation and Data Collection}

EIT employs measurement of voltages along the boundary of a test specimen. First, electrodes are affixed to the surface of the specimen as shown in Figure 5(a); the electrodes are used to introduce electrical currents and to measure voltage. Typically, electrodes are installed equidistant from one another so as to simplify the forward problem model. In this study the adjacent electrode protocol to data collection is adopted (Heikkinen et al., 2002). In this approach, a regulated current (DC or AC) is applied to a pair of adjacent electrodes. On the remaining electrodes, the resulting voltage is measured and recorded. The process is repeated using the same electrical excitation until every combination of adjacent electrode pairs has been employed.

\section{Formulation of the Forward Problem}

The flow of electrical current within a $2 \mathrm{D}$ body, $\Omega$, can be modeled by the 2D Laplce equation:

$$
\nabla \cdot[\sigma(x, y) \nabla \phi(x, y)]=I(x, y)
$$

(a)

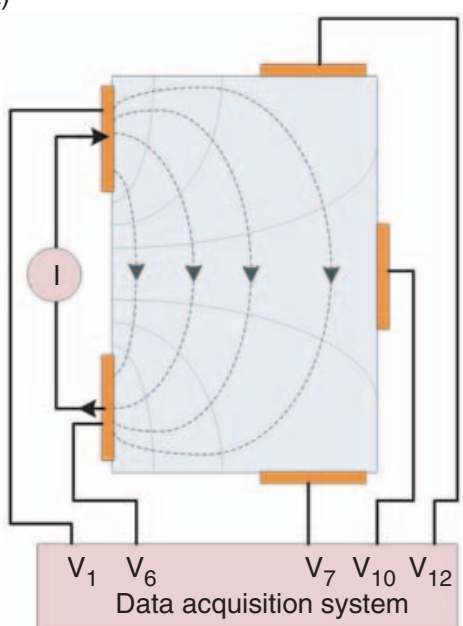

(b)

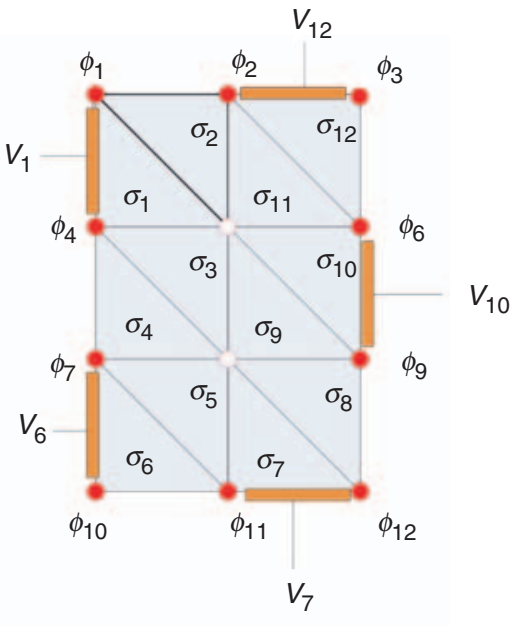

where $\sigma, \varphi$, and $I$ are conductivity, electric potential, and current, respectively, at point $(x, y)$. Assuming current is applied only on the boundary of the body, the righthand side of Equation (4) is then set equal to zero. For a known distribution of conductivity, the forward problem allows the electrical potential to be uniquely calculated at every point in the body based on the current applied at the body boundary, $\partial \Omega$, if Dirichlet (voltage is continuously measurable on the body boundary) and Neumann (the integral of current along the boundary is zero) boundary conditions are assumed. Regardless, analytical solutions to the Laplace equation are not tractable except for specimens defined by simple geometries and minimal conductivity variations (Lionheart et al., 2005). Hence, numerical solutions are generally pursued with finite difference, boundary element, and finite element methods all previously proposed. The finite element method (FEM) though is the most common numerical approach for modeling Equation (4).

The FEM formulation adopted in this study is termed the complete electrode model (CEM). This approach begins by meshing the body into discrete triangular elements as shown in Figure 5(b). The conductivity of the $j$ th element is assumed constant, $\sigma_{j}$. Variation of electric potential across the body is assumed to be a linear sum of electrical potential at element vertices, $\phi_{\tau}$, multiplied by predefined shape functions, $w_{i}$ (Lionheart et al., 2005):

$$
\phi(x, y)=\sum_{1}^{N} \phi_{i} w_{i}(x, y)
$$

where the shape function takes the unit value at the ith vertex and zero at all other vertices. $N$ corresponds to the number of nodes in the mesh. Along the element boundaries, different shape functions can be employed but 2nd order polynomials are adopted in this study. Assuming voltages are measured on electrodes two at a time with the first electrode held fixed as the reference 
electrode, then the vector of electrodes can be approximated as (Vauhkonen, 1997):

$$
V=\sum_{1}^{L-1} V_{j} n_{j}
$$

where $n_{j}=[1,0,0, \ldots,-1, \ldots, 0]^{\mathrm{T}}$ (with -1 in the $j t h$ indexed term of the vector) and $V_{j}$ is the voltage of the $j$ th element. Due to the lack of differentiability of the shape functions, $w$ and $n$, variational methods are employed to yield the weak form of the 2D Laplace equation. The solution for each element is assembled into a global linear equation for the specimen:

$$
\mathbf{A x}=\mathbf{b}
$$

where $\mathbf{A} \in \mathfrak{R}^{(N+L-1) x(N+L-1)}$ is the sparse system matrix calculated using the element conductivities, $\mathbf{x}=[\mathbf{\Phi V}]^{\mathrm{T}}$, $\mathbf{b}=\left[\begin{array}{ll}\mathbf{0} & \mathbf{I}\end{array}\right]^{\mathrm{T}}, \boldsymbol{\Phi}=\left[\begin{array}{lll}\phi_{1} & \phi_{2} & \ldots\end{array} \phi_{N}\right]^{\mathrm{T}}, \mathbf{V}=\left[\begin{array}{lll}V_{1} & V_{2} \ldots, V_{L}\end{array}\right]^{\mathrm{T}}$, and $\mathbf{I}=\left[\begin{array}{llllll}1 & 0 & 0 & \ldots & -1 \ldots 0\end{array}\right]^{\mathrm{T}}$. For the example presented in Figure 5(b), twelve triangular elements, twelve vertices $(N=12)$, and five electrodes $(L=5)$ are used. Therefore, $\mathbf{V}=\left[\begin{array}{llllll}V_{1} & V_{6} & V_{7} & V_{10} & V_{12}\end{array}\right]^{\mathrm{T}}$, and $\mathbf{I}=\left[\begin{array}{lllll}1 & -1 & 0 & 0 & 0\end{array}\right]^{\mathrm{T}}$. While theoretically the forward problem can be solved for $\mathbf{x}$ by $\mathbf{x}=\mathbf{A}^{-1} \mathbf{b}$, the sparsity of $\mathbf{A}$ requires more robust approaches to inversion such as the use of LU decomposition, among others.

\section{Solution to the Inverse Problem}

The EIT problem is the inverse of the forward problem; in other words, EIT finds the optimal mapping of conductivity, $\sigma(x, y)$, based upon voltage measurements along the boundary. The solution of the inverse problem requires the forward problem to be run repeatedly as the assumed distribution of conductivity is varied $\left(\sigma^{\prime}=\sigma+\Delta \sigma\right)$ so as to minimize the mean square error between the measured voltages and the model predicted electric potentials:

$$
f\left(\sigma^{\prime}\right)=\frac{1}{2}\left\|\phi\left(\sigma^{\prime}\right)-V\right\|^{2}
$$

The changes in conductivity, $\Delta \sigma$, between successive runs of the forward problem are based on the NewtonRaphson iterative method and are expressed as:

$$
\Delta \sigma=-\left[\phi^{\prime}(\sigma)^{T} \phi^{\prime}(\sigma)\right]^{-1} \phi^{\prime}(\sigma)[\phi(\sigma)-V]
$$

where $\phi^{\prime}(\sigma)$ is the Jacobian matrix of the FEM boundary potential.

The Jacobian matrix, $\phi^{\prime}(\sigma)$, represents the voltage changes at the electrodes due to small perturbations in the assumed conductivity distribution. With boundary potentials depending on element conductivity nonlinearly, the ill-conditioned nature of the Jacobian typically requires regularization techniques (for example, Tikhonov regularization) so as to provide stable iterative convergence to the final conductivity distribution (Barber, 1989; Lionheart et al., 2005).

Unfortunately, the ill-posed inverse problem is defined by an underdetermined set of equations. As a result, a single set of boundary voltages corresponding to an applied current is insufficient to accurately map the body conductivity. Therefore, boundary voltage measurements corresponding to multiple applied current distributions are needed to yield a stable and accurate solution. For this reason, the adjacent electrode approach applies current to every combination of adjacent electrodes. Repeated boundary measurements provide sufficient data to render the EIT inverse problem overdetermined.

\section{Experimental Methods}

\section{ECC TEST SPECIMENS}

Engineered cementitious composites (ECC), a unique strain hardening FRCC designed using polymeric fibers (Li et al., 2002), are adopted to evaluate the application of EIT sensing for the measurement of strain and the identification of crack damage. ECC are constructed using Type 1 Portland cement, silica sand as a fine aggregate, fly ash and short polyvinyl alcohol (PVA) fibers for reinforcement. To control the growth of cracks and to attain strain hardening behavior in tension, the surface of the PVA fiber is chemically treated to tailor the micro-mechanical properties of the fiber-matrix interface. Only a small amount of PVA fibers is necessary to attain optimal mechanical properties; in this study, a $2 \%$ volume fraction of PVA fibers is used. To build test specimens, a wet ECC mixture is poured into molds where they remain for 7 days to harden. Once seven days have passed, the specimens are removed from the molds and cured until testing which occurs no earlier than 28 days after casting. The first set of test specimens constructed are ECC plates that are $30.5 \mathrm{~cm}$ long and with cross sectional areas of 7.6 by $1.3 \mathrm{~cm}^{2}$ (Figure 6(a)). The second specimen employed is an ECC beam which is more representative of a realistic structural element. The beam is $140 \mathrm{~cm}$ long, $15.2 \mathrm{~cm}$ deep, and $7.6 \mathrm{~cm}$ wide. For both sets of specimens, no steel reinforcement is employed.

\section{Data Acquisition}

To conduct EIT sensing on the test specimens, each specimen is instrumented with copper electrodes. Adhesive copper tape $(6.3 \mathrm{~mm}$ wide and $0.7 \mathrm{~mm}$ thick) is attached to the surface of the test specimens to serve as electrodes. To ensure the copper-cement contact is conductive, additional silver colloidal paste is used to attach the electrodes. AC electrical signals are applied to an adjacent set of electrodes using a high-precision current generator (Keithly 6221). As the AC current is 
applied to the element, electric potential (voltage) is measured at all of the other electrodes using a standard laboratory data acquisition system (National Instruments). Standard shielded coaxial wires, roughly $1 \mathrm{~m}$ in length, are used to attach the data acquisition system to the copper electrodes. MATLAB is used to execute the tomographic reconstruction algorithms. The FEM model of each test specimen is meshed with 384 triangular elements.

Strain is also measured by three traditional methods for many of the loaded specimens. First, metal foil strain gages (Texas Measurements) with nominal resistances of $120 \Omega$ and gage factors of 2.1 are installed on the surface of the ECC specimens using epoxy. An additional approach to measuring strain is by optical methods using the OptoTrak Certus motion capture system. The system consists of a 3020 OptoTrak camera position sensor $(111 \mathrm{~cm} \times 31.5 \mathrm{~cm} \times 21.5 \mathrm{~cm})$, markers and a system control unit. The markers are reflective nodes (approximate diameter $1 \mathrm{~cm}$ ) that are attached to the specimen surface using standard glue. 2D motion of the markers is accurately measured by the 3020 OptoTrak camera position sensor with a resolution of $<0.01 \mathrm{~mm}$. To achieve this resolution, the camera position sensor is placed $2 \mathrm{~m}$ from the instrumented test specimen. The last approach is to calculate strain using the actuator displacement as measured by the load frame's linear variable differential transformer (LVDT).

\section{Monotonic Tensile Loading}

Four rectangular ECC plate specimens are prepared for monotonic tensile loading. First, 32 copper electrodes are attached to the sides of the plate as shown in Figure 6(a). On the long sides of the specimen, 12 electrodes are attached to each side; the shorter sides each have 4 electrodes attached. The electrodes are installed to be equidistant from one another. The specimens are labeled as specimen MT1 through MT4. Twelve OptoTrak markers are glued to the front surface of specimen MT1; the markers are oriented in two vertical rows and separated by $3 \mathrm{~cm}$ from one another. The marker orientation divides the plate specimen into five regions labeled as region 1 through 5 . Along the vertical center line of the specimen, five metal foil strain gages are attached; the gages are separated such that each region has its own strain gage. Strain gages and OptoTrak markers are not installed on specimens MT2 through MT4.

Specimen MT1 is gripped by an MTS load frame and monotonically loaded in tension. Prior to the application of axial load, the copper electrodes are used to perform EIT sensing of the specimen. This data will be used to derive a baseline conductivity map of the unloaded plate specimen. The load frame is commanded to apply tension load to the plate with the actuator displacement controlled. Applied force and actuator displacement are recorded from which stress and strain of the specimen can be calculated. The actuator is paused at $0.05,0.1,0.2,0.3,0.4,0.5,0.75,1,1.25$, and $1.5 \%$ strain. When paused, EIT sensing is conducted so as to collect electrical data for reconstruction of conductivity maps of the instrumented specimen. In addition, strain and displacement of the OptoTrak markers are measured. After $1.5 \%$ strain has been achieved, the test is terminated.

Specimens MT2 through MT4 are loaded into the MTS load frame for monotonic tensile loading. Again, before axial load is applied to the specimens, EIT sensing is conducted to obtain baseline tomographic data. Next, each specimen is loaded with the actuator operated in displacement control mode to strain levels of
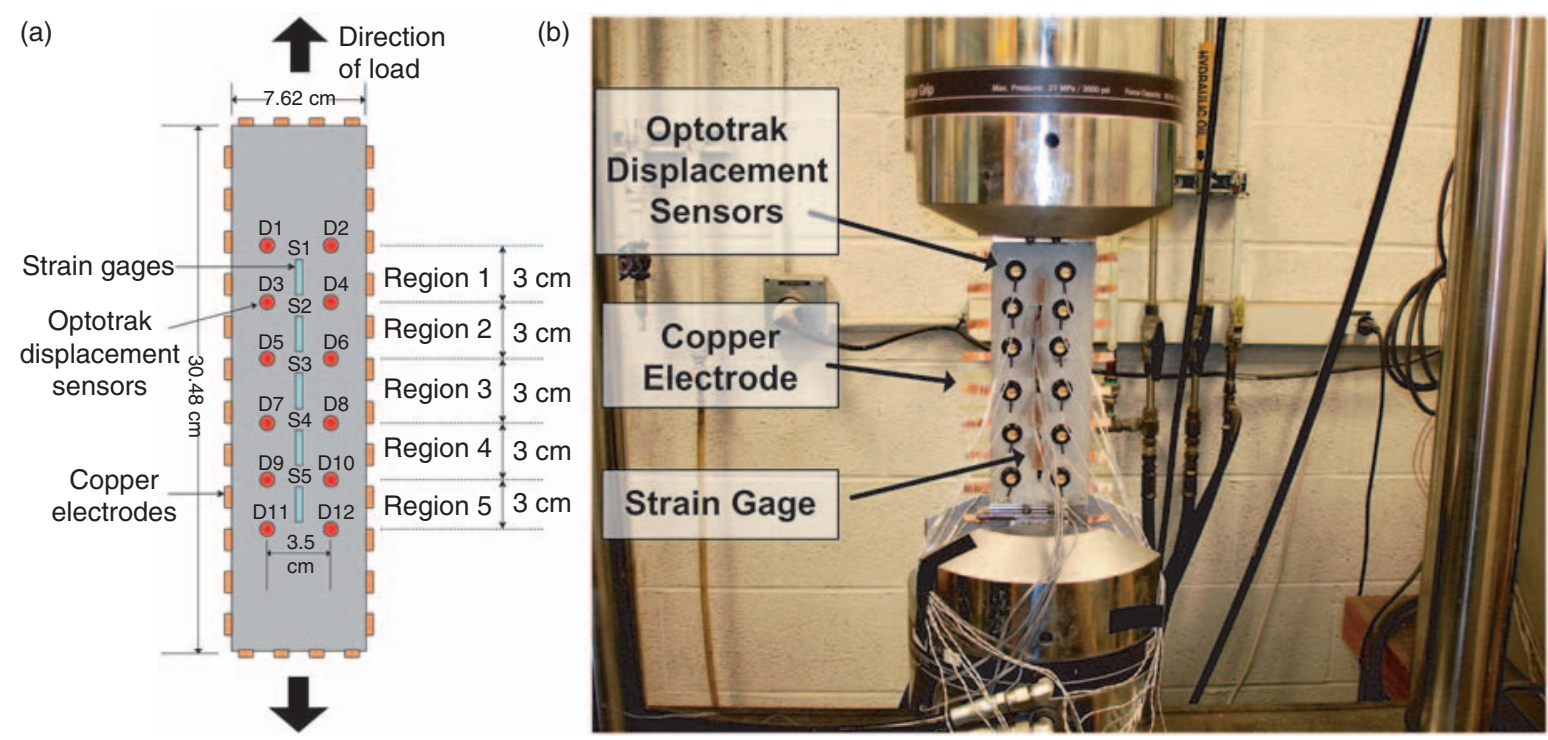

Figure 6. (a) ECC plate specimen under monotonic and cyclic axial loading; (b) ECC plate specimen loaded into the tensile load frame. 
$0.5,1$, and $2.4 \%$ strain. At each strain level, the load is paused and EIT sensing conducted. After $2.4 \%$ strain, each specimen is loaded until failure. At the point of failure, EIT sensing is again performed.

\section{Cyclic Axial Loading}

Again, 32 copper electrodes are attached to the boundary of plate specimen CT1 in the same configuration as specimens MT1 through 4 (Figure 6(a)). Before the specimen is gripped in the MTS load frame, EIT sensing is performed to derive a baseline conductivity map of the unloaded specimen. The specimen is then gripped in the MTS load frame and two tensioncompression cycles are applied. The specimen is cyclically loaded with the following peak strains: first, $0.32 \%$ strain in tension, second, $0.5 \%$ strain in compression, third, $1.2 \%$ strain is tension, forth, $1 \%$ strain in compression, and then finally $2 \%$ strain in tension. After $2 \%$ tensile strain is achieved, the specimen is monotonically loaded until failure. Along the two cycles of loading, the application and relaxation of axial load is paused and EIT conductivity maps are calculated.

\section{Monotonic Three Point Bending}

The ECC beam is instrumented with 32 copper electrodes mounted to the bottom face of the beam. A section roughly $38.1 \mathrm{~cm}$ long and $7.6 \mathrm{~cm}$ wide is delineated in the center of the beam by the electrodes (Figure 7). Twelve electrodes are attached along each of the long sides of this region while four electrodes are attached on each of the shorter sides. The beam is placed upon the bed of an Instron general purpose load frame; roller supports spaced $121.9 \mathrm{~cm}$ apart support the beam at two ends while an actuator applies load at the center of the beam's top face. An EIT conductivity map is acquired prior to the application of load. Once load is applied, the test is paused at displacements of 0.2 and $0.6 \mathrm{~cm}$ so that EIT conductivity maps of the beam's lower face can be acquired. After a displacement of $0.6 \mathrm{~cm}$ is achieved, the beam is loaded till failure.

\section{RESULTS AND DISCUSSION}

\section{Specimen MT1}

Specimen MT1 is monotonically loaded in tension in order to estimate the sensitivity of the piezoresistive effect of ECC materials. The stress-strain curve of the monotonically loaded plate is presented in Figure 8(a). The plate initiates strain hardening at $\sim 0.2 \%$ strain (as calculated from the load frame displacement). The application of tension is paused three times while the plate is elastic (denoted as P1, P2, and P3). After strain hardening, the test is again paused as denoted by points P4 through P10. Each time the test is paused, an EIT conductivity map of the plate is obtained. The conductivity of the specimen is averaged across each of the specimen's five regions (as delineated in Figure 6(a)) and compared to the average conductivity prior to the application of load (effectively at P0). The percent change in average conductivity versus the average strain (as calculated from the load frame displacement) is plotted in Figure 8(b) for each specimen region. As can be seen in the plot, each region exhibits a nearly linear change in conductivity as a function of strain.

The strain calculated using the load frame displacement represents an average strain for the entire specimen. In contrast, the OptoTrak sensor system can measure strain in localized regions of the specimen. Similarly, the EIT conductivity maps provide a measurement of the ECC conductivity over the complete instrumentation area. As a result, for each of the regions defined by the location of the OptoTrak markers (regions 1 through 5), the localized strains measured by the OptoTrak camera are compared to the average resistivity of the region. To calculate the average resistivity, the conductivities of the triangular elements of the EIT conductivity map are averaged and inverted to yield the average resistivity. For each region of
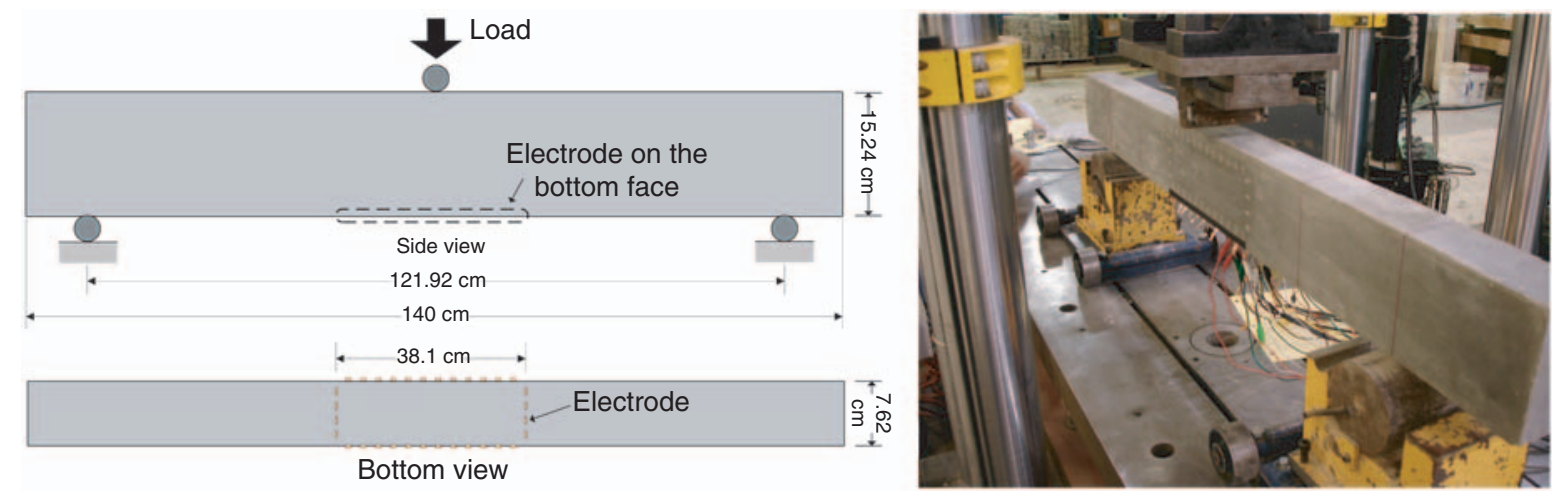

Figure 7. Unreinforced ECC beam loaded in 3-point bending with conductivity measured on the bottom beam face. 

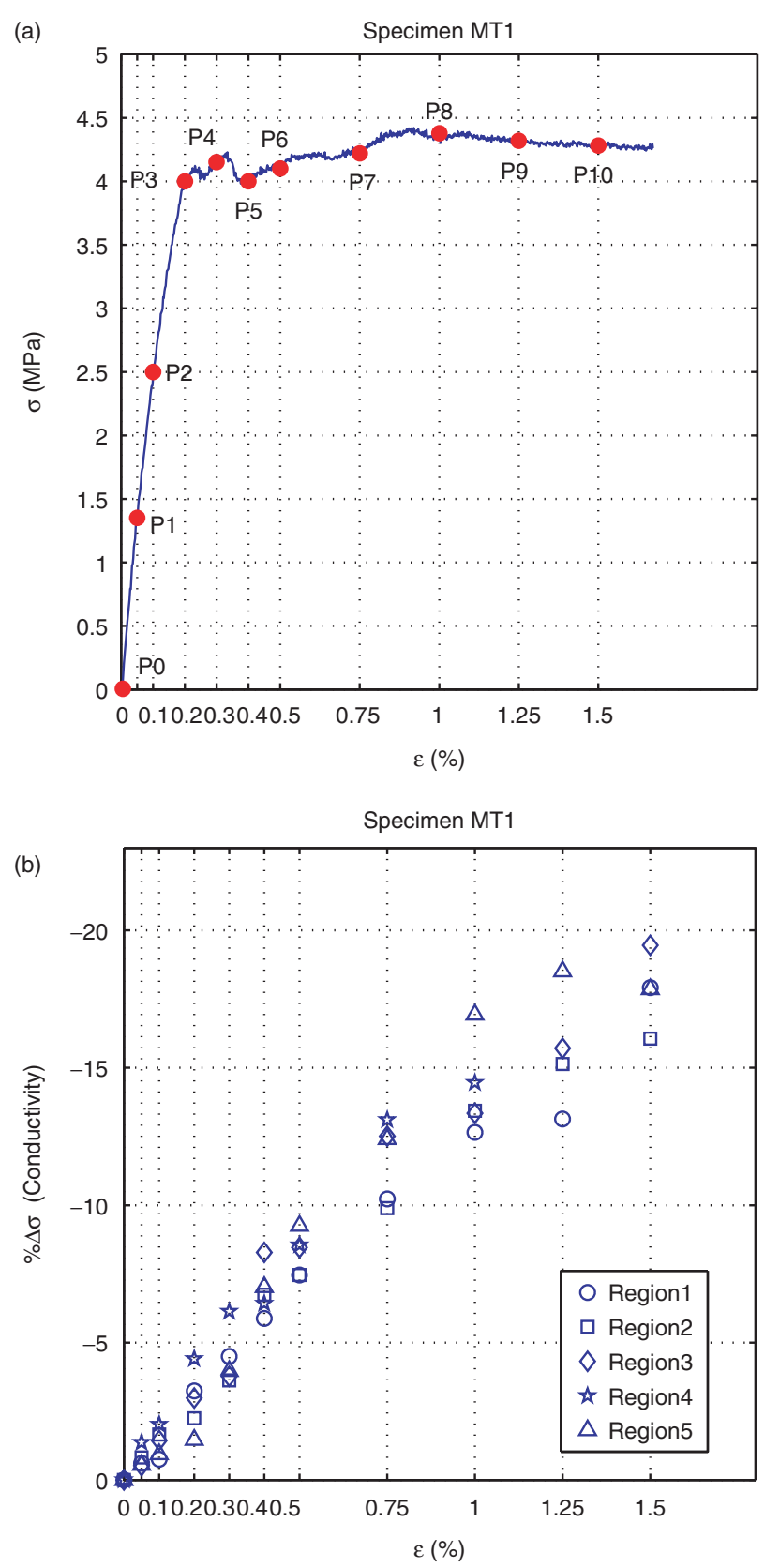

Figure 8. Monotonic tensile loading of specimen MT1: (a) stressstrain response; (b) percentage change of conductivity as a function of the average specimen strain.

specimen MT1, the averaged resistivity is plotted versus the local strain as measured by the OptoTrak system in Figure 9. The piezoresistive effect is evident with resistivity increasing in tandem with strain. Furthermore, the resistivity changes are fairly linear with gage factors of $15.0,14.3,15.6,15.4$, and 15.4 for regions 1 through 5 , respectively.

\section{Specimen MT2 - MT4}

Specimens MT2, MT3, and MT4 are loaded monotonically in uniaxial tension until failure (damage localization). During loading, stress-strain responses are recorded as shown in Figures 10(a), 11(a), and 12(a), respectively. All three specimens undergo strain hardening after reaching $0.25 \%$ strain. The ultraductility of the ECC material is evident by the ultimate strain levels reached by each of the three plates; specimens MT2, MT3, and MT4 all fail at strains in excess of $2.5 \%$.

When the specimens achieve $0.5 \%$ strain, the application of load is paused and an EIT conductivity map is acquired. To observe a change in conductivity, the conductivity map acquired at point A (i.e., unloaded) will be subtracted from those acquired during loading. As can be seen in Figures 10(b), Figures 11(b), and Figures 12(b), the maps of the change in conductivity of the specimens at point $\mathrm{B}$ reveal reductions in conductivity consistent with strain (i.e., piezoresistive effect). Furthermore, regions of microcracking which occur during strain hardening are evident in the conductivity maps. For example, in specimen MT2, a thin band of concentrated conductivity change in the center of the element reveals the strain hardening microcracking. Specimens MT3 and MT4 also have regions of microcracking evident towards the left-side of their EIT conductivity maps.

Monotonic tensile loading of the specimens continues until $1 \%$ strain is achieved. At point $\mathrm{C}$, the average conductivity for each specimen reduces consistently with strain. However, regions of microcracking where conductivity reductions are greater have grown significantly. For example, for specimen MT4, the thin region of microcracking at $0.5 \%$ strain has grown to occupy nearly half of the specimen. Similarly, in specimen MT2, the region of microcracking is in the center of the specimen and occupies nearly a quarter of the specimen length.

The tests are continued until damage localizes into large cracks (i.e., failure). The large cracks can be seen in the EIT conductivity maps as major reductions in conductivity, some as large as $500 \mathrm{nS}-\mathrm{cm}^{-1}$. For example, in Figure 10(b), two large cracks can be seen in the EIT conductivity map at the two ends of the specimen. The cracks imaged in the EIT maps precisely capture the location and geometric orientation of the true damage state of the specimen as pictured in Figure 10(c). The locations of the cracks in the actual test specimen are highlighted using a red felt tip marker to enhance the comparison. For specimen MT3, the macrocrack forms in the center of the specimen as can be seen in the final EIT conductivity map (Figure 11(b)) and the picture of the final specimen (Figure 11(c)). Again, in specimen MT4, the ECC plate develops a large crack towards the left-side of the specimen (Figure 12(c)). This crack is successfully captured by the EIT conductivity map at $3.0 \%$ strain (Figure 12(b)). 

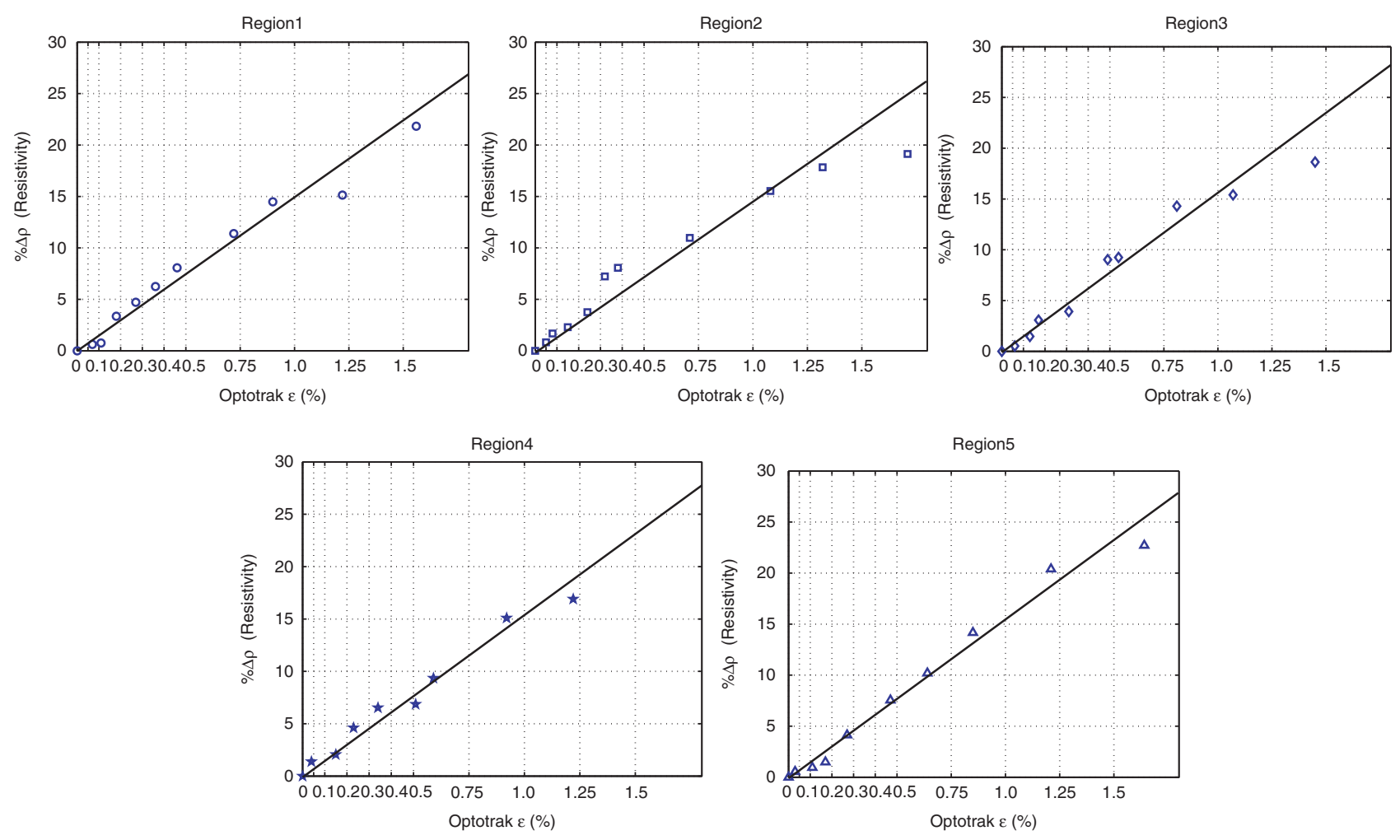

Figure 9. Change in average resistivity of region 1 through 5 vs strain as measured by the OptoTrak optical sensors installed in that region.

\section{Specimen CT1}

Plate specimen CT1 is loaded cyclically in axial tension and compression. Again, the distribution of change in specimen conductivity (i.e. conductivity minus the baseline conductivity) is mapped at multiple points along the cyclic loading profile. As can be observed in Figure 13(a), the specimen is first loaded in tension until a tensile strain of $0.32 \%$ (point B). At this strain level, a narrow band of microcracking can be observed towards the left-side of the specimen as shown in the EIT conductivity maps of Figure 13(b). As the specimen is unloaded back to $0 \%$ strain (point $\mathrm{C}$ ), the change in conductivity in the region of microcracking recovers, suggesting the closure of the cracks. The plate is then loaded in compression to $0.5 \%$ strain (point D). When loaded in compression, the narrow crack field once again becomes evident although the conductivity reduction is less pronounced than when the element is loaded in tension. Even though the cracks introduced in tension have closed, because they do not close perfectly, some reduction in conductivity is expected. When the specimen is reloaded in tension to $1 \%$ strain (point $\mathrm{F}$ ), the microcracks from point $\mathrm{B}$ reopen while additional microcracks form, yielding a larger field of microcracking at the left-side of the specimen. As the ECC specimen is further loaded in tension to $1.3 \%$ strain (point G), a second field of microcracks emerges near the center of the specimen. Thereafter, the specimen is loaded to $1 \%$ strain in compression (point I). Again, the microcracks present in the specimen can still be observed in the EIT conductivity maps even though they have closed. This is likely due to their inexact closure and the occurrence of some crushing at the crack surface. After achieving a peak compressive strain of $1 \%$, the specimen is loaded in tension until failure, which occurs at $2.8 \%$ strain (point L). When loaded in tension, the microcracking field in the center of the specimen continues to grow until a large millimeter wide crack is introduced on the right-side of the specimen at $2.8 \%$ tensile strain. The location and geometry of the crack is evident in the EIT conductivity map. The EIT conductivity map compares well with a photo of the failed specimen (Figure 13(c)).

At each point of cyclic loading, the percent change in conductivity is averaged over the entire specimen. This per cent change in conductivity is superimposed over the chronological plot of applied strain, as shown in Figure 14. The per cent change in conductivity varies in linear proportion with strain when loaded in tension. If the gage factor of the specimen is calculated at the points of peak tension (points $B, G, L$ ), the gage factor is found to be 8.5, 13.1, and 15.4, respectively. The increase in gage factor is due to the accumulation of microcracking in the specimen. When the specimen is unloaded between successive tension-compression peaks, the accumulation of microcracking prevents the specimen 


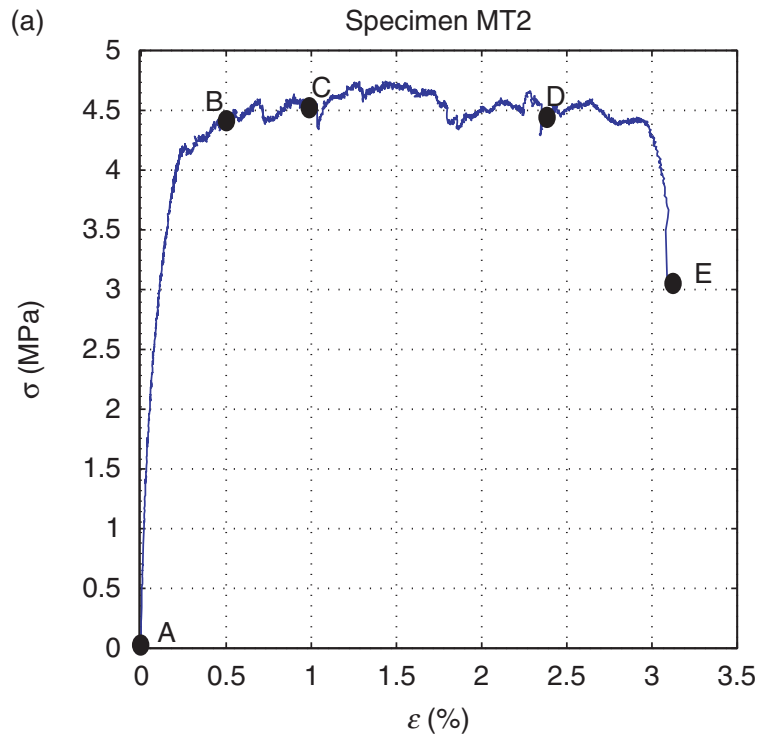

(b)
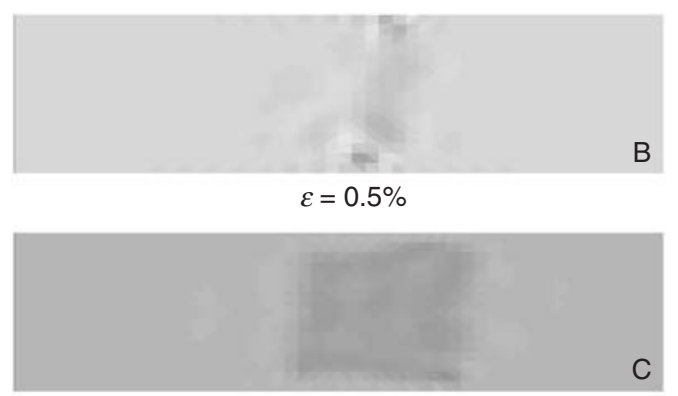

$\varepsilon=1.0 \%$

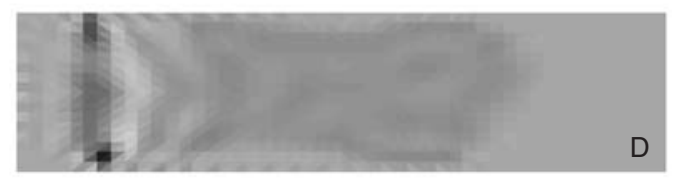

$\varepsilon=2.4 \%$

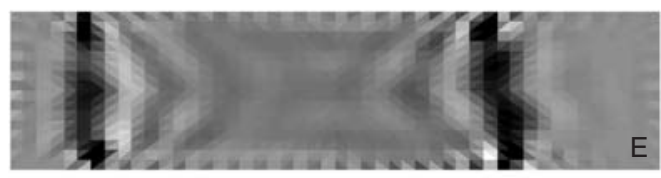

$\varepsilon=3.1 \%$

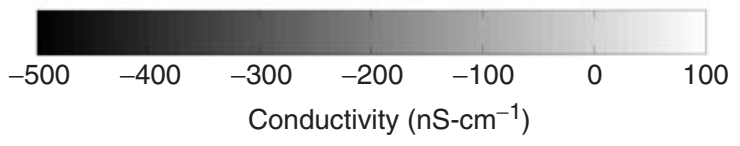

(c)

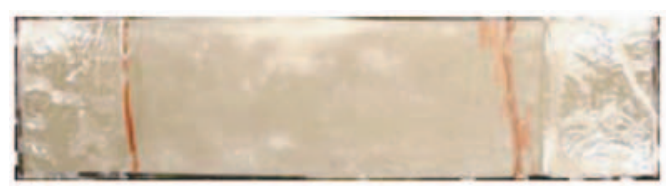

Figure 10. Monotonic tensile loading of specimen MT2: (a) stressstrain response; (b) change in conductivity from the baseline for four levels of strain; (c) final specimen with cracks highlighted.

from fully recovering its initial conductivity. As can be seen, in Figure 14, the residual change in conductivity at points $\mathrm{C}, \mathrm{E}, \mathrm{H}$, and $\mathrm{J}$ is $0.7,1.0,3.1$, and $3.7 \%$, respectively. When the element is placed in compression,

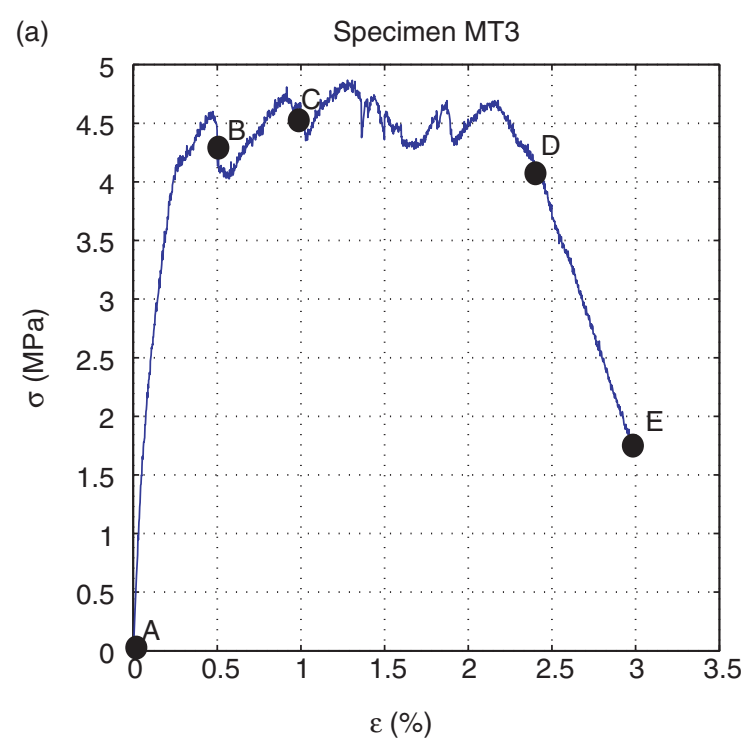

(b)
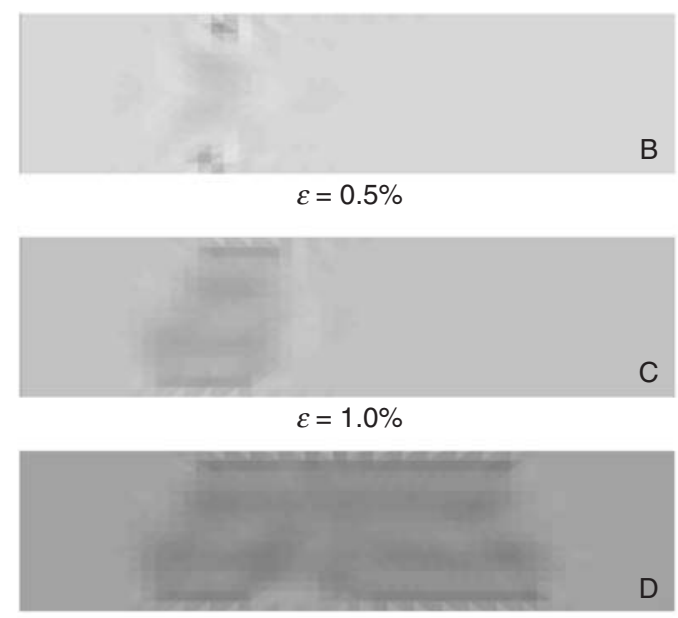

$\varepsilon=2.4 \%$
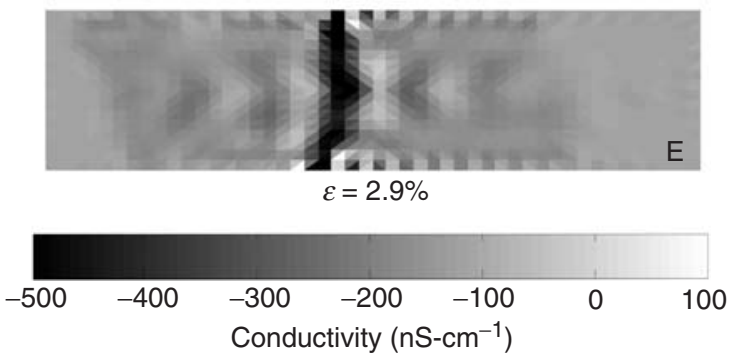

(c)

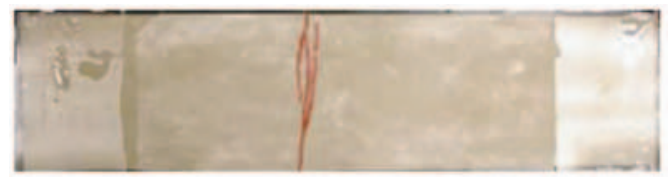

Figure 11. Monotonic tensile loading of specimen MT3: (a) stressstrain response; (b) change in conductivity from the baseline for four levels of strain; (c) final specimen with crack highlighted.

the specimen conductivity still reduces but at a much smaller rate in compression than when in tension. The effective gage factor for the element is calculated at points $\mathrm{D}$ and $\mathrm{I}$ as -3.0 and -5.2 , respectively. 
(a)

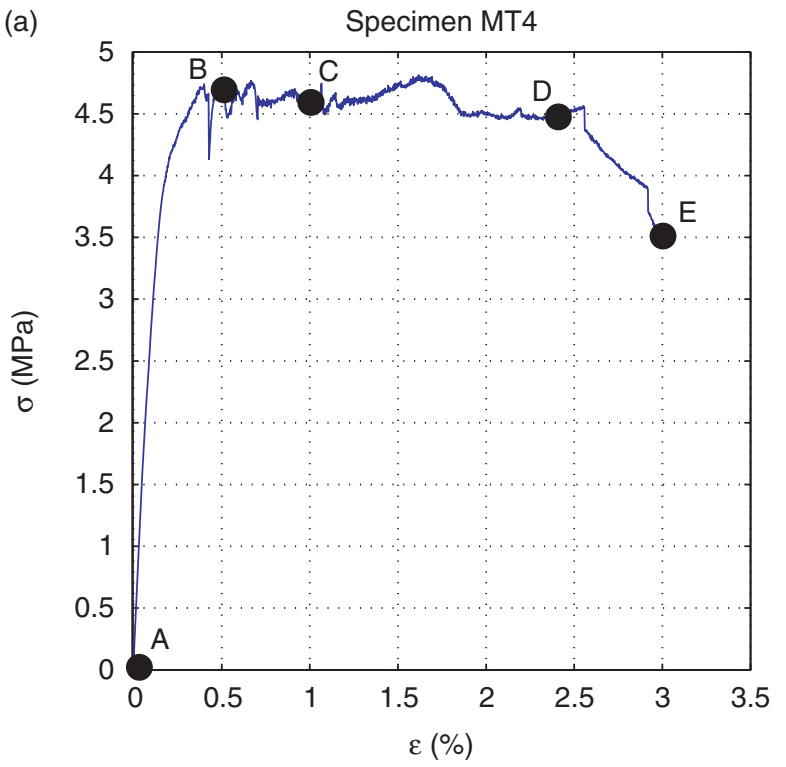

(b)
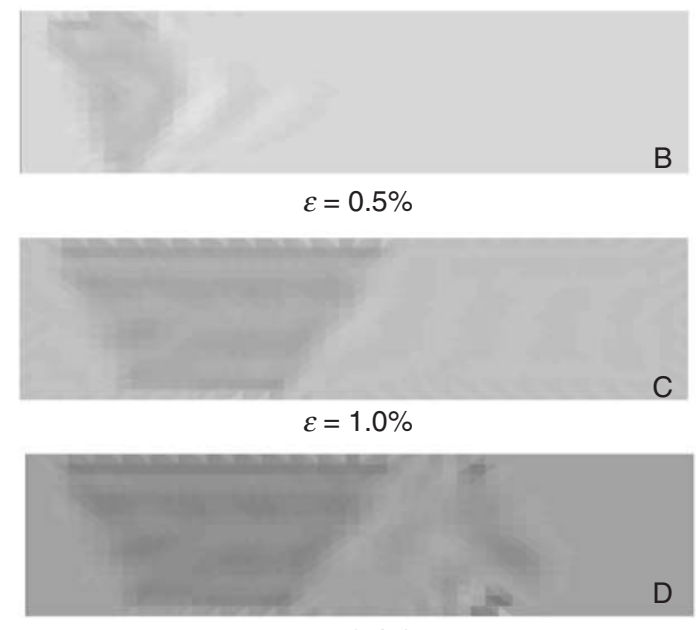

$\varepsilon=2.4 \%$

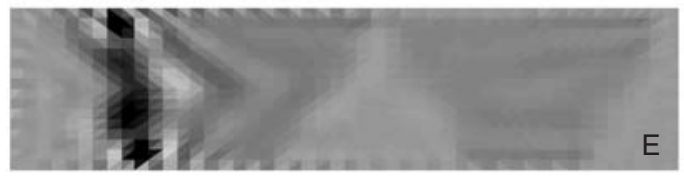

$\varepsilon=3.0 \%$

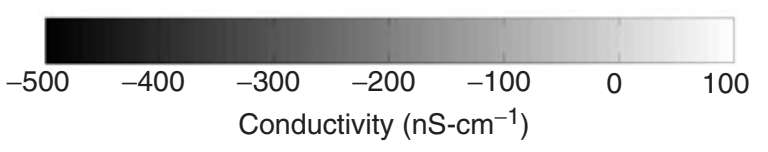

(c)

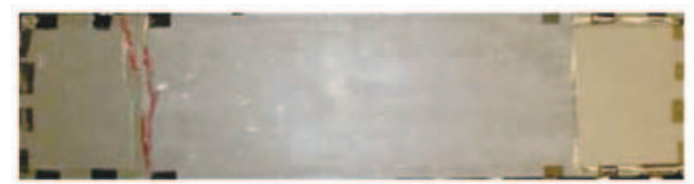

Figure 12. Monotonic tensile loading of specimen MT4: (a) stressstrain response; (b) change in conductivity from the baseline for four levels of strain; (c) final specimen with crack highlighted.

\section{Beam Specimen}

In the last set of experiments, the ECC beam specimen is loaded in 3-point bending while EIT conductivity maps of the lower face of the beam are taken at four points along the monotonically applied forcedisplacement curve (denoted as points $\mathrm{A}, \mathrm{B}, \mathrm{C}$, and $\mathrm{D}$ in Figure 15(a)). The absolute EIT conductivity maps are presented in Figure 15(c). The formation of cracking initiates at point $\mathrm{B}$ with a field of microcracking observable in the center of the EIT conductivity map. The field of microcracking appears to resemble a ' $V$ ' shape with one side of the beam experiencing more microcracking than the other. As the load is applied, the beam begins to soften at a deflection of $0.4 \mathrm{~cm}$; softening is due to the formation of a macrocrack. At point $\mathrm{C}$, the EIT conductivity map reveals the crack at the center of the beam; the crack width is measured using a crack gage to be $\sim 3 \mathrm{~mm}$ wide. The crack is further widened by displacing the beam to $0.9 \mathrm{~cm}$ (point $\mathrm{D}$ ). At this point, the change in absolute conductivity is significantly greater (a reduction of $1600 \mathrm{nS}-\mathrm{cm}^{-1}$ ). With the load still applied, the crack opening is $\sim 5 \mathrm{~mm}$. Pictures of the final cracked specimen are presented in Figure 15(b).

\section{CONCLUSIONS}

The lasting contribution of this work is the introduction of EIT as a powerful new NDE tool for health monitoring of cementitious structures. EIT offers true multi-dimensional sensing that can be automated for unattended long-term operation in actual concrete structures. In this study, EIT sensing is validated upon ECC specimens loaded in axial tension, axial compression and bending. EIT conductivity maps reveal the piezoresistive nature of ECC structural elements loaded in tension. The tensile gage factor of ECC, as determined by EIT conductivity mapping, is shown to be between 13 and 15 . While the piezoresistivity of cementitious materials have been proposed for selfsensing strain, the authors are of the opinion that this approach would be challenging to practically apply in actual field structures. As witnessed in this work, microcracking in the cementitious specimen alters the gage factor; gage factors are shown to increase with the accumulation of cracking. Other challenges also exist including the sensitivity of the material's electrical properties with environmental influences like temperature and humidity.

The more likely use of EIT sensing is for damage characterization of cement-based structures. As one of the few truly distributed sensing approaches, EIT has the ability to accurately locate cracks as well as quantify their geometric features. As this work has shown, the geometric propagation of dense fields of microcracks, 
strain hardening, and crack localization in FRCC elements were all easily captured by the EIT conductivity maps. This work largely restricted its application to $2 \mathrm{D}$ surfaces of the ECC specimens. However, the EIT formulation is general and can be applied to $3 \mathrm{D}$. For example, electrodes mounted to the outer surface of structural elements would be capable of imaging the element's internal structure. This could be powerful for

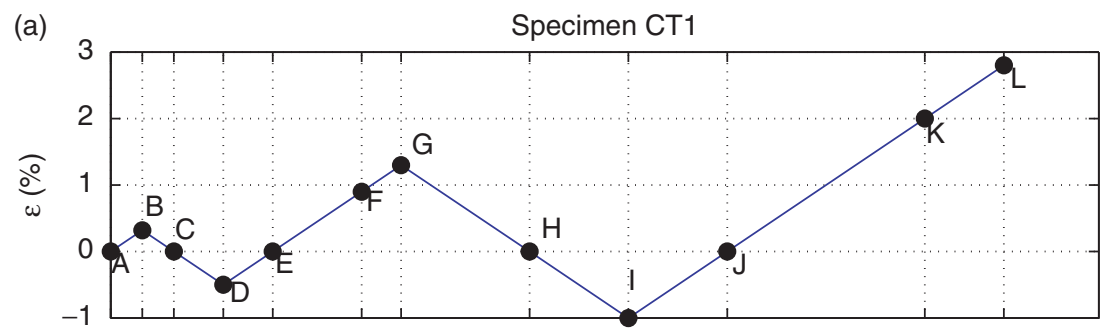

Chronological mapping point

(b)

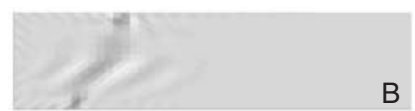

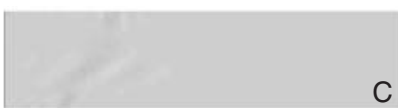
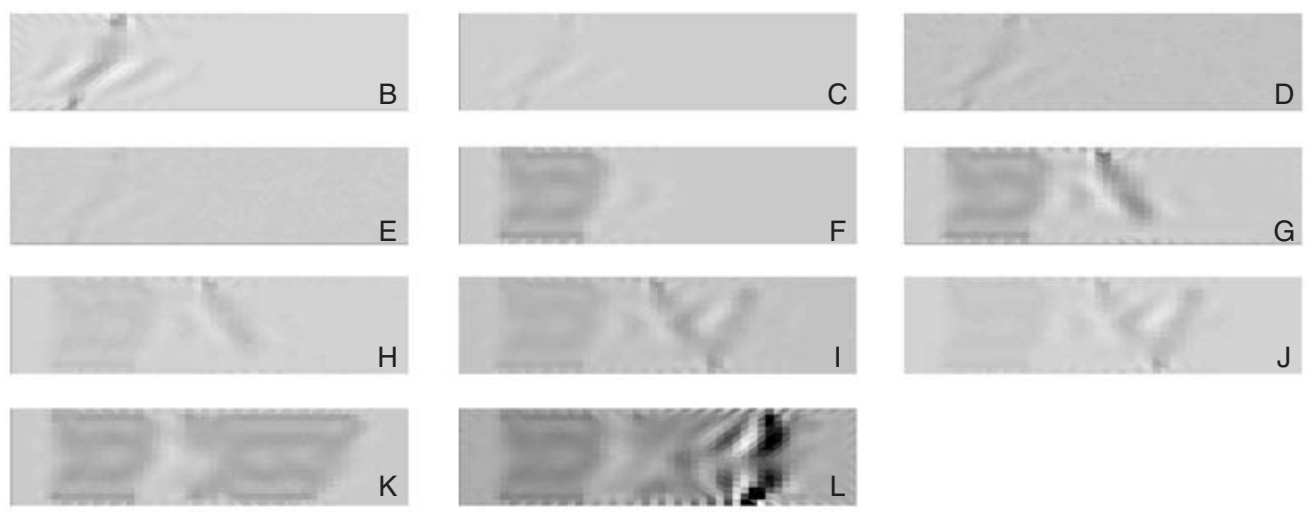

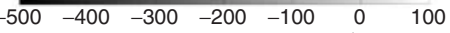
Conductivity $\left(\mathrm{nS}^{\left.-\mathrm{cm}^{-1}\right)}\right.$

(c)

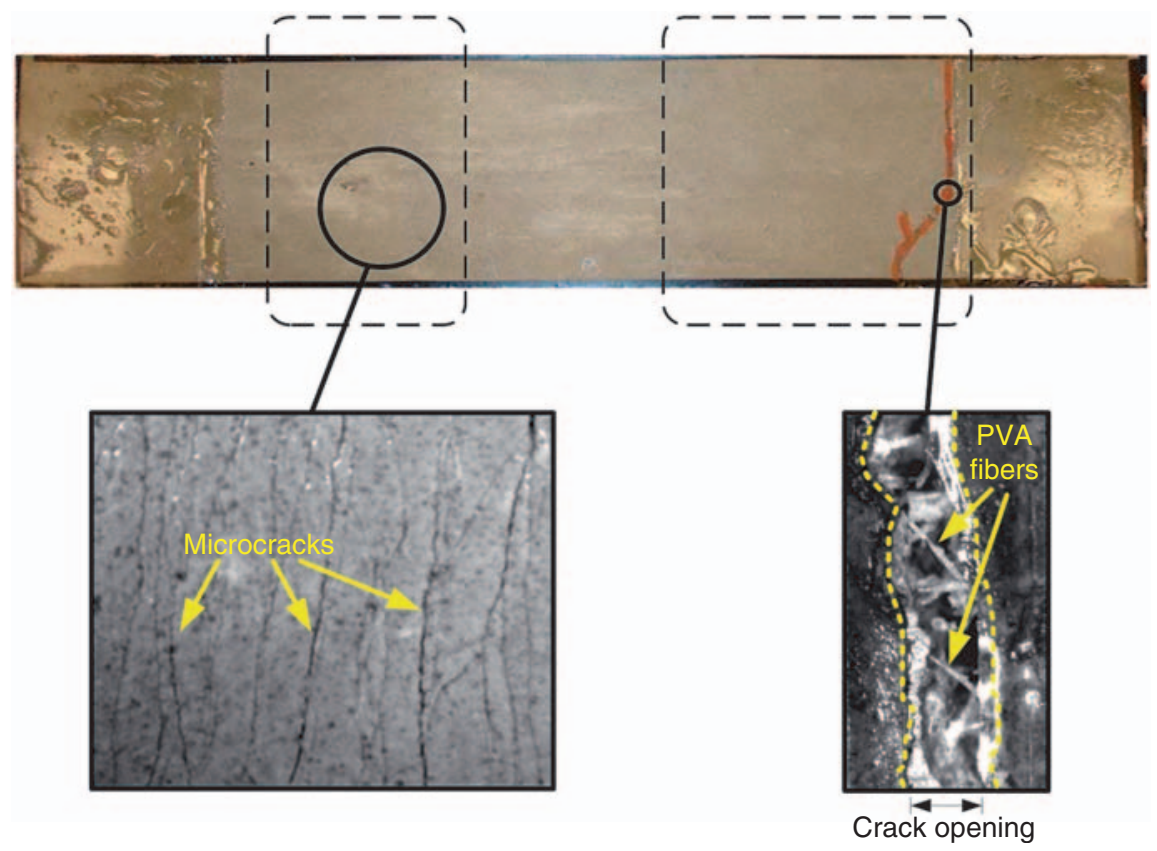

Figure 13. Cyclic axial loading of specimen CT1: (a) chronological application of tensile and compressive strain; (b) mapping of conductivity changes at points $B$ through L; (c) picture of failed specimen (point $L$ ) with close-up views of cracking fields and fibers bridging a macro-scale crack. 
identifying cracks below the surface that are impossible to detect during visual inspection.

While this work lays a firm foundation for EIT sensing in civil structures, additional work is needed to

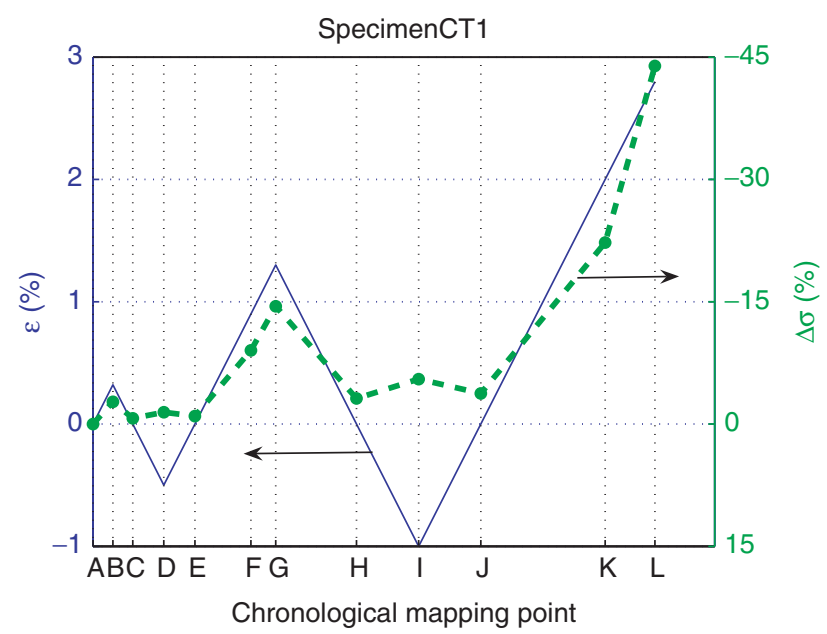

Figure 14. Average conductivity change for each load point superimposed with the applied strain pattern.

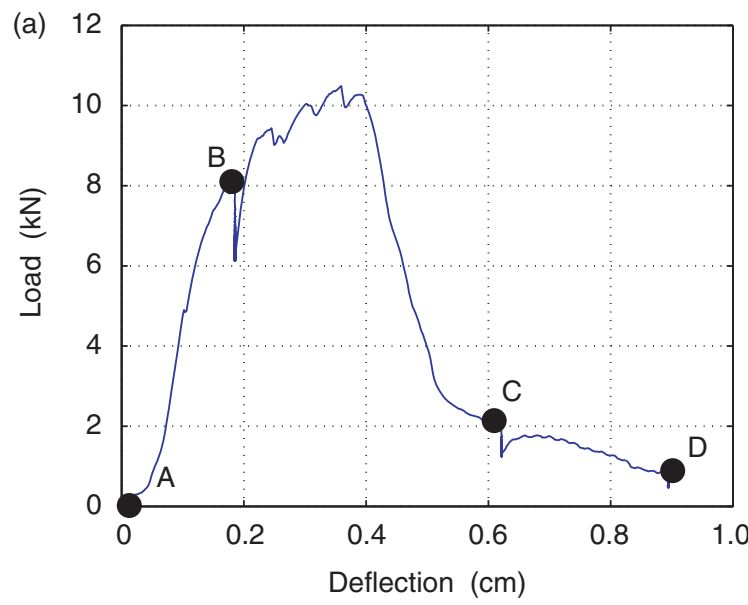

(c)
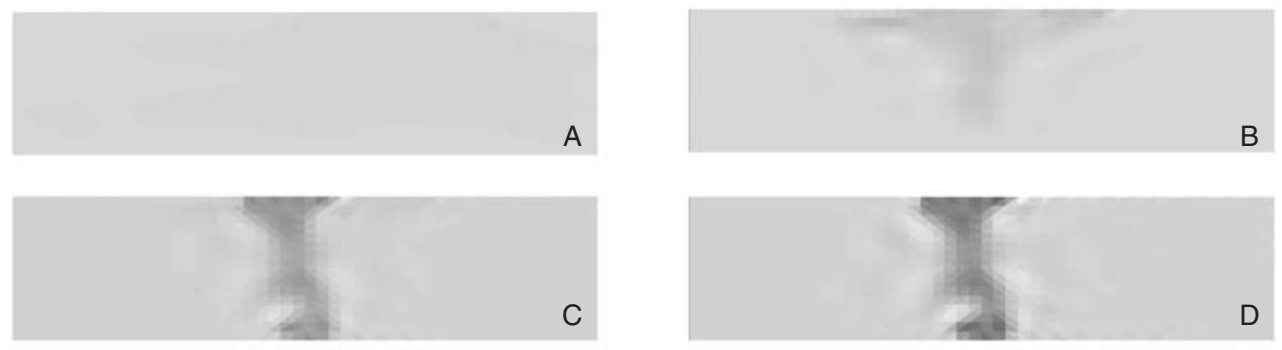

8001000120014001600180020002200240026002800

Conductivity ( $\mathrm{nS}-\mathrm{cm}^{-1}$ )

Figure 15. Beam specimen 1 under 3-point bending: (a) load-deflection curves; (b) side and bottom face damage with cracks highlighted; (c) absolute conductivity maps at points $A$ through $D$. further develop this novel technique. This study only considered the use of ECC materials for EIT sensing; other cementitious materials including concrete must be explored. The inclusion of conductive fibers in a cement matrix opens new and exciting avenues of exploration since fiber interfaces and volume fractions can be varied to adjust the nominal conductivity and piezoresistive gage factor of the material. An additional advantage of conductive fibers is that conductive fiber FRCC materials experience an increase in conductivity when loaded in compression (Chung, 2003). This is in contrast to the polymeric fibers employed in this study; polymeric fibers are non-conducting resulting in decreases in conductivity when specimens are loaded in compression. Other challenges envisioned for EIT sensing is the inclusion of steel reinforcement in structural specimens. The presence of reinforcement steel in the structure could alter the EIT map. However, the location of reinforcement is generally known a priori and can therefore be included at the outset of the EIT inverse solution. This would preserve the accuracy of the EIT approach when mapping the conductivity of just the cementitious material.

(b)
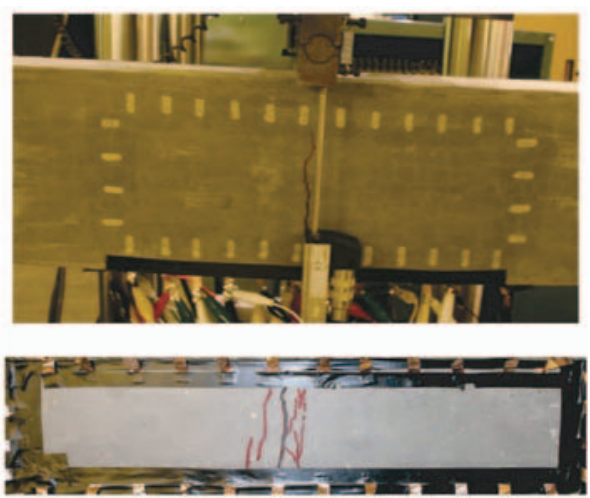


\section{ACKNOWLEDGMENTS}

This research was partially funded by the National Science Foundation under Grant CMMI-0724022. The authors would like to express their gratitude to Professor Victor C. Li (University of Michigan) for offering unfettered access to engineered cementitious composite materials and for allowing us to use his MTS810 load frame during the experimental phase of this study. For measurement of strain in the plate specimens by optical means, the assistance provided by Prof. Gustavo Parra-Montesinos (University of Michigan) and Mr Hai Dinh (University of Michigan) was greatly appreciated. Additional assistance was provided by Dr Shunzhi Qian (TU-Delft) and Dr En-Hua Yang (University of Michigan).

\section{REFERENCES}

ACI 1998. Causes, Evaluation and Repair of Cracks in Concrete Structures, Report Number ACI224.1R-93, American Concrete Institute, Farmington Hills, MI.

Balaguru, P.N. and Shah, S.P. 1992. Fiber-reinforced Cement Composites, McGraw-Hill, New York, NY.

Barber, D.C. 1989. "A Review of Image Reconstruction Techniques for Electrical Impedance Tomography," Medical Physics, $16: 162-169$.

Barsoukov, E. and Macdonald, J.R. (eds) 2005. Impedance Spectroscopy Theory, Experiment, and Applications, Wiley, Hoboken, NJ.

Bungey, J.H., Millard, S.G. and Grantham, M.G. 2006. Testing of Concrete in Structures, Taylor and Francis, London, UK.

Calleja, J. 1953. "Determination of Setting and Hardening Time of High-alumina Cements by Electrical Resistance Techniques," Journal of the American Concrete Institute, 25:249-256.

Carino, N.J. 2004. "Stress Wave Propagation Methods," In: Handbook on Nondestructive Testing of Concrete, Malhotra V.M. and Carino N.J. (eds), CRC Press, Boca Raton, FL.

Chung, D.D.L. 2001. "Cement-based Electronics," Journal of Electroceramics, 6:75-88.

Chung, D.D.L. 2003. Multifunctional Cement-based Materials, Marcel-Dekker, New York, NY.

Doebling, S.W., Farrar, C.R. and Prime, M.B. 1998. "A Summary Review of Vibration-based Damage Identification Methods," Shock and Vibration Digest, 30:91-105.

Gowers, K.R. and Millard, S.G. 1999. "Measurement of Concrete Resistivity for Assessment of Corrosion Severity of Steel Using Wenner Technique," ACI Materials Journal, 96:536-541.

Hammond, E. and Robson, T.D. 1955. "Comparison of Electrical Properties of Various Cements and Concretes," The Engineer, 199:114-115.

Han, N., van Beek, A. and Koenders, E.A.B. 2005. "Electrical Methods," In: Advanced Testing of Cement Based Materials during Setting and Hardening - Final Report of RILEM TC 185$A T C$, In: Reinhardt, H.W. and Grosse, C.U. (eds), Technical Report 31, RILEM, Bagneux, France.

Hansson, I.L.H. and Hansson, C.M. 1983. "Electrical Resistivity Measurement of Portland Cement Based Materials," Cement and Concrete Research, 13:675-683.

Heikkinen, L.M., Vilhunen, T., West, R.M. and Vauhkonen, M. 2002. "Simultaneous Reconstruction of Electrode Contact Impedances and Internal Electrical Properties: II. Laboratory Experiments," Measurement Science and Technology, 13:1855-1861.
Hou, T.C. and Lynch, J.P. 2005a. "Conductivity-Based Strain Monitoring and Damage Characterization of Fiber Reinforced Cementitious Structural Components," In: Proceedings of the SPIE - The International Society for Optical Engineering, 5765:419-429.

Hou, T.C. and Lynch, J.P. 2005b. "Monitoring Strain in Engineered Cementitious Composites using Wireless Sensors," In: Proceedings of the 11th International Conference on Fracture, Turin, Italy.

Jung, Y.C., Na, W.B., Kundu, T. and Ehsani, M. 2000. "Damage Detection in Concrete Using Lamb Waves," In: Proceedings of SPIE - The International Society for Optical Engineering, 3995:448-458.

Kim, Y.Y., Fischer, G. and Li, V.C. 2004. "Performance of Bridge Deck Link Slabs Designed with Ductile Engineered Cementitious Composite," ACI Structural Journal, 101:792-801.

Kratzig, W.B., Meyer, I.F. and Meskouris, K. 1989. "Damage Evolution in Reinforced Concrete Members Under Cyclic Loading," In: Proceedings of the 5th International Conference on Structural Safety and Reliability, San Francisco, CA, pp. $795-802$.

Kunieda, M. and Rokugo, K. 2006. "Recent Progress on HPFRCC in Japan Required Performance and Applications," Journal of Advanced Concrete Technology, 4:19-33.

Lauer, K.R. 2004. "Magnetic/Electrical Methods," In: Handbook on Nondestructive Testing of Concrete, Malhotra, V.M. and Carino, N.J. (eds.), CRC Press, Boca Raton, FL.

Li, V.C., Wu, C., Wang, S., Ogawa, A. and Saito, T. 2002. "Interface Tailoring for Strain Hardening PVA-ECC," ACI Materials Journal, 99:463-472.

Li, H., Xiao, H.G. and Ou, J.P. 2006. "Effect of Compressive Strain on Electrical Resistivity of Carbon Black-filled Cement-based Composites," Cement and Concrete Composites, 28:824-828.

Lionheart, W., Polydorides, N. and Borsic, A. 2005. "The Reconstruction Problem," In: Electrical Impedance Tomography: Methods, History, and Applications, Holder, D S. (ed.), IoP, London, UK.

Luangvilai, K., Punurai, W. and Jacobs, L.J. 2002. "Guided Wave Technique to Characterize Repaired Concrete," In: AIP Conference Proceedings, pp. 1220-1226.

Mayer, J.W. and Lau, S.S. 1990. Electronic Materials Science: for Integrated Circuits in Si and GaAs, Macmillan, New York, NY.

McCarter, W.J. and Brousseau, R. 1990. "The A.C. Responses of Hardened Cement Paste," Cement and Concrete Research, 20:891-900.

Millard, S.G. 1991. "Reinforced Concrete Resistivity Measurement Techniques," In: Proceedings of the Institution of Civil Engineers, Part 2: Research and Theory, 91:71-88.

Mindess, S. 2004. "Acoustic Emission Methods," In: Handbook on Nondestructive Testing of Concrete, Malhotra, V.M. and Carino, N.J. (eds), CRC Press, Boca Raton, FL.

Na, W.B., Kundu, T., and Ehsani, M.R. 2002. "Ultrasonic Guided Waves for Steel Bar Concrete Interface Testing," Materials Evaluation, 60:437-444.

Naaman, A.E. and Chandrangsu, K. 2004. "Innovative Bridge Deck System using High-performance Fiber-Reinforced Cement Composites," ACI Structural Journal, 101:57-64.

Ouyang, C., Landis, E. and Shah, S.P. 1991. "Damage Assessment in Concrete using Quantitative Acoustic Emission," Journal of Engineering Mechanics, 117:2681-2698.

Park, S., Ahmad, S., Yun, C.B. and Roh, Y. 2006. "Multiple Crack Detection of Concrete Structures using Impedance-based Structural Health Monitoring Techniques," Experimental Mechanics, 46:609-618.

Park, Y.J. and Ang, A.H.S. 1985. "Mechanistic Seismic Damage Model for Reinforced Concrete," Journal of Structural Engineering, 111:722-739.

Park, G., Cudney, H.H. and Inman, D.J. 2000. "Impedance-based Health Monitoring of Civil Structural Components," Journal of Infrastructure Systems, 6:153-160. 
Parra-Montesinos, G.J. 2005. "High-performance Fiber-reinforced Cement Composites: An Alternative for Seismic Design of Structures," ACI Structural Journal, 102:669-675.

Peled, A., Torrent, J.M., Mason, T.O., Shah, S.P. and Garboczi, E.J. 2001. "Electrical Impedance Spectra to Monitor Damage During Tensile Loading of Cement Composites," ACI Material Journal, 98:313-322.

Raghavan, A. and Cesnik, C.E.S. 2007. "Review of Guided-wave Structural Health Monitoring," Shock and Vibration Digest, 39:91-114.

Reza, F., Yamamuro, J.A., Batson, G.B. and Lee, J.S. 2003. "Smart Behavior of Carbon Fiber Cement Composites in Compact Tension," In: Proceedings of the 16th ASCE Engineering Mechanics Conference, Seattle, WA.

Rose, J.L. and Ditri, J.J. 1990. "Ultrasonic Computed Tomography Considerations in the NDE of Solid Materials," In: IEEE 1990 Ultrasonics Symposium Proceedings, pp. 991-995.

Shah, S.P. and Choi, S. 1999. "Nondestructive Techniques for Studying Fracture Processes in Concrete," International Journal of Fracture, 98:351-359.
Stang, H. and Pedersen, C. 1996. "HPFRCC - Extruded Pipes," In: Proceedings of the 4th Materials Engineering Conference, Washington, DC, pp. 261-270.

Vauhkonen, M. 1997. Electrical Impedance Tomography and Prior Information, PhD Thesis, Kuopio University, Kuopio, Finland.

Vilhunen, T., Kaipiom, J.P., Vauhkonen, P.J., Savolainen, T. and Vauhkonen, M. 2002. "Simultaneous Reconstruction of Electrode Contact Impedances and Internal Electrical Properties: I. Theory," Measurement Science and Technology, 13:1848-1854.

Webster, J.G. 1990. Electrical Impedance Tomography, Hilger, Bristol, England.

Whiting, D.A. and Nagi, M.A. 2003. Electrical Resistivity of Concrete - A Literature Review, PCA R\&D Serial No. 2457, Portland Cement Association: Skokie, IL.

Wight, J., Parra-Montesinos, G. and Canbolat, A. 2006. "HPFRCC Coupling Beams for Earthquake-resistant Wall Structures," In: Proceedings of the IABSE Symposium on Structures and Extreme Events, Lisbon, Portugal, pp. 114-115.

Zhdanov, M.S. and Keller, G.V. 1994. Geoelectrical Methods in Geophysical Exploration, Elsevier, Amsterdam. 